\title{
WRF Model Methodology for Offshore Wind Energy Applications
}

\author{
Evangelia-Maria Giannakopoulou and Regis Nhili \\ EDF Energy R\&D UK Centre, 52 Grosvenor Gardens, London SW1W 0AU, UK \\ Correspondence should be addressed to Evangelia-Maria Giannakopoulou; marilia.giannakopoulou@edfenergy.com
}

Received 6 February 2014; Accepted 24 March 2014; Published 23 April 2014

Academic Editor: Huei-Ping Huang

Copyright ( 2014 E.-M. Giannakopoulou and R. Nhili. This is an open access article distributed under the Creative Commons Attribution License, which permits unrestricted use, distribution, and reproduction in any medium, provided the original work is properly cited.

\begin{abstract}
Among the parameters that must be considered for an offshore wind farm development, the stability conditions of the marine atmospheric boundary layer (MABL) are of significant importance. Atmospheric stability is a vital parameter in wind resource assessment (WRA) due to its direct relation to wind and turbulence profiles. A better understanding of the stability conditions occurring offshore and of the interaction between MABL and wind turbines is needed. Accurate simulations of the offshore wind and stability conditions using mesoscale modelling techniques can lead to a more precise WRA. However, the use of any mesoscale model for wind energy applications requires a proper validation process to understand the accuracy and limitations of the model. For this validation process, the weather research and forecasting (WRF) model has been applied over the North Sea during March 2005. The sensitivity of the WRF model performance to the use of different horizontal resolutions, input datasets, PBL parameterisations, and nesting options was examined. Comparison of the model results with other modelling studies and with high quality observations recorded at the offshore measurement platform FINO1 showed that the ERA-Interim reanalysis data in combination with the 2.5-level MYNN PBL scheme satisfactorily simulate the MABL over the North Sea.
\end{abstract}

\section{Introduction}

The offshore wind energy has recently become a rapidly growing renewable energy resource worldwide, with several offshore wind projects in development in different planning stages $[1,2]$. Despite this, a better understanding of the interaction between the MABL and the offshore wind turbines is needed in order to contribute to a better energy capture and cost-effectiveness [2]. The MABL is less studied than the planetary boundary layer (PBL) over land and some obvious reasons are the difficulties, scarcity, and costs of obtaining offshore observations. However, during the last years a great effort has been made in finding solutions [3]. For example, mesoscale meteorological models are increasingly considered lately for wind energy assessment and yield calculations. The advantage of the mesoscale models in WRA relies on their ability to simulate with reasonable accuracy the lower parts of the boundary layer, including important atmospheric properties such as the atmospheric energy balance and stability [4]. However, the usage of any mesoscale model for wind energy applications requires a proper validation process to understand the accuracy and limitations of the model.

The impact of the atmospheric stability on the wind and turbulence profiles and on the wind turbine wakes raises the need to consider in the WRA of an offshore wind farm the stability conditions observed in the MABL $[5,6]$. Different stability conditions result in different shear conditions which in turn lead to different wind speed distributions across the rotor swept area. The different velocity distributions can significantly affect the power production and fatigue loads on the wind turbine [7]. For example, it is well known that wind power losses, as a result of wake losses, are largest in stable atmospheric conditions and least in unstable and/or neutral conditions [6]. Therefore, a precise estimation of the wind and stability conditions of an offshore site is required. Currently, stability is not measured in traditional WRA campaigns and more accurate WRA could be obtained if the wind climate is classified not only by wind direction but also by stability classes. 
In the mesoscale models the vertical stratification is inherently included and the different PBL schemes influence the accuracy of the simulated winds and atmospheric stratification in the MABL [8]. For instance, some PBL parameterisations are best in unstable/neutral stratifications, some others are best in stable atmospheric conditions, and some in both [3]. It is also widely known that the performance of the PBL schemes in the mesoscale models depends on the area of interest, the meteorological variables examined, and season and time of day considered, and one cannot identify a best model configuration in a general sense [9]. The most common approach to deal with this problem is to carry out statistical studies over a sensible set of model configurations and finally use the PBL scheme that reproduces better the observations in an average sense.

The attention of this study has been focused on the development of a mesoscale methodology by using the weather research and forecasting (WRF) model [10] so as to accurately simulate the wind conditions and to reproduce the stability effects on the wind profile over the MABL in the North Sea. The present work describes the verification of the WRF model, by comparing the model results with that of other modelling studies (e.g., $[8,11]$ ) and with high quality observations recorded at the FINO1 offshore platform in the North Sea. For this verification process, several WRF modelling simulations have been performed during March 2005. In particular, different horizontal resolutions, PBL parameterizations, initial and boundary conditions, and nesting options were tested. The high probability $(20 \%)$ of occurrence of stable to very-stable atmospheric stratification situations in the spring and early summer at the FINO1 platform and the impact of the high stability on the wind profile increases the need to focus on the stable atmospheric conditions and include them in our WRF model configuration and mesoscale methodology $[3,5]$. A time period during which all the atmospheric stability conditions are observed are also investigated in this study.

A description of the verification process including information about the data sources and the statistics used for analysis is given in Section 2.1. Section 2.2 focuses on the WRF model setup and the process followed for testing its performance. Description of the synoptic conditions during the stable period in March 2005 and presentation of the WRF results for this case study with a number of key derived statistics are provided in Section 3. In the same section, presentation of the WRF results for the whole March 2005 with statistical metrics and error analysis is also given. Conclusions follow in Section 4.

\section{Materials and Methods}

2.1. Verification Process. Two main steps of the verification process are the definition of the data sources and the definition of the verification statistics to be produced by the analysis.

2.1.1. Observational Data: FINO1 Measurements. The FINO1 offshore platform in Southern North Sea is located $45 \mathrm{~km}$ north of the Borkum island (latitude: $54.0^{\circ} \mathrm{N}$ and longitude: $6.35^{\circ} \mathrm{E}$ ) and performs multilevel measurements of wind speed, wind direction, air temperature, relative humidity, and air pressure since 2004. The height of the measurement mast is about $100 \mathrm{~m}$ above mean sea level (MSL). Three ultrasonic instruments (of $10 \mathrm{~Hz}$ temporal resolution) are located at $41.5 \mathrm{~m}, 61.5 \mathrm{~m}$, and $81.5 \mathrm{~m}$ height on northwesterly oriented booms. In addition, eight cup anemometers with the lower resolution of $1 \mathrm{~Hz}$ are installed at different heights starting from $34 \mathrm{~m}$ upto about $100 \mathrm{~m}$ (every $10 \mathrm{~m}$ ) on booms mounted in southeast direction of the meteorological mast (e.g., $[8,11])$.

A list of parameters used for the analysis of the meteorological conditions and for the comparison with the WRF model results is shown in Table 1. In Table 1, we also provide the heights of the recorded parameters and the sensor types including their accuracy according to Cañadillas [6]. For the WRF model validation we used data from the cup anemometers in order to have the best spatial coverage to describe the vertical profiles of wind speed and wind direction. According to Deutsches Windenergie-Institut (DEWI, German Wind Energy Institute) scientists at the RAVE 2012 conference [12], the sonic anemometer data were sparse and were associated with errors especially during the period 2004-2007. In general, from 2004 to 2011 the availability of the cup anemometers at the FINO1 platform was about $98 \%$, while the availability of the sonic anemometers was approximately $83 \%$ [12].

2.1.2. Define Verification Statistics. The following statistical metrics have been used in this study to verify the performance of the WRF model when compared with the FINO1 observations. More details on the verification statistics could be found in [13].

Bias or mean error (ME) is defined as the mean of the differences between the WRF simulated meteorological parameters and the FINO1 observations. In particular, the mean error is calculated for each hour of data and the time average (over the period we have considered to study) bias is then provided for each measuring height of the FINO1 platform.

Mean absolute error (MAE) is defined as the quantity used to measure how close the observed values are to the modelled ones. The MAE is given by

$$
\operatorname{MAE}=\frac{1}{n} \sum_{i=1}^{n}\left|x_{i}-y_{i}\right|,
$$

where $\left|x_{i}-y_{i}\right|$ is the absolute error with $x_{i}$ and $y_{i}$ to represent the modelled and the observed values at the FINO1 met mast, respectively. $n$ is the sample size.

Standard Deviation (STD) of the ME is defined as the dispersion of the biased values around the mean value. A low standard deviation indicates that the data points tend to be very close to the mean; high standard deviation indicates that the data points are spread out over a large range of values. The STD uses the following formula:

$$
\sigma=\sqrt{\frac{\sum_{i=1}^{n}\left(x_{i}-\bar{x}\right)^{2}}{(n-1)}},
$$

where $\sigma$ is the standard deviation and $\bar{x}$ is the sample mean. 
TABLE 1: Meteorological parameters with their associated heights and the sensor types including their accuracy [6] at the FINO1 offshore platform.

\begin{tabular}{lcc}
\hline Variable & Heights $(\mathrm{m})$ LAT & Sensor type (accuracy) \\
\hline Wind speed $(\mathrm{m} / \mathrm{s})$ (cup anemometer) & $34,41.5,51.5,61.5,71.5,81.5,91.5,104.5$ & Vector A100LK-WR-PC3 $( \pm 0.01 \mathrm{~m} / \mathrm{s})$ \\
Wind direction $($ degree $)$ & $41.5,51.5,61.5,71.5,81.5,91.5$ & Thies wind vane classic $\left( \pm 1^{\circ}\right)$ \\
Air temperature $\left({ }^{\circ} \mathrm{C}\right)$ & $30,41.5,52,72,101$ & Pt-100 $\left( \pm 0.1 \mathrm{~K}\right.$ at $\left.0^{\circ} \mathrm{C}\right)$ \\
Relative humidity $(\%)$ & $34.5,90$ & Hydrometer, Thies $( \pm 3 \% \mathrm{RH})$ \\
Air pressure $(\mathrm{hPa})$ & 22.5 & Barometer, Vaisala $( \pm 0.03 \mathrm{hPa})$ \\
\hline
\end{tabular}

Root Mean Square Error (RMSE) is a frequently used measure of the difference between values predicted by a model and the values actually observed. It measures the average magnitude of the error and it is defined as the measure of the combined systematic error (bias) and random error (standard deviation). Therefore, the RMSE will only be small when both the variance and the bias of an estimator are small. The RMSE uses the following formula:

$$
\mathrm{RMSE}=\sqrt{\sigma^{2}+\bar{x}^{2}}
$$

where $\bar{x}$ is the sample mean and $\sigma$ is the standard deviation.

Pearson correlation coefficient $(R)$ is defined as the measure of the linear dependence between the WRF results and the FINO1 data, giving a value between +1 and -1 inclusive. It thus indicates the strength and direction of a linear relationship between these two variables. A value of 1 implies that a linear equation describes the relationship between WRF and the observations perfectly, with all data points lying on a line for which the WRF values increase as the data values increase. The correlation is -1 in case of a decreasing linear relationship and the values in between indicates the degree of linear relationship between the WRF model and the observations. The formula for the Pearson product moment correlation coefficient is

$$
R=\frac{\sum_{i=1}^{n}\left(x_{i}-\bar{x}\right)\left(y_{i}-\bar{y}\right)}{\sqrt{\sum_{i=1}^{n}\left(x_{i}-\bar{x}\right)^{2}\left(y_{i}-\bar{y}\right)^{2}}},
$$

where the $\bar{x}$ and $\bar{y}$ are, respectively, the sample means of the WRF results and the measurements.

2.2. Model and Setup. In this study, the numerical weather prediction (NWP) model of the National Centre for Atmospheric Research (NCAR): advanced WRF model, version 3.4 [10] was used. The model was run for this project on a Xeon X54 system at EDF R\&D in France, with 96 CPUs. The WRF model is based on the fully compressible, nonhydrostatic Euler equations and for the purposes of this research the Lambert conformal projection was chosen. A third order Runge-Kutta (RK3) integration scheme and Arakawa C-grid staggering were used for temporal and spatial discretization, respectively. The modelling setup including the selected domains and the initial and boundary conditions as well as the physics schemes is described below. The strategy followed for the WRF modelling setup followed up to a certain point the strategy of previous WRF studies (e.g., $[14,15])$.

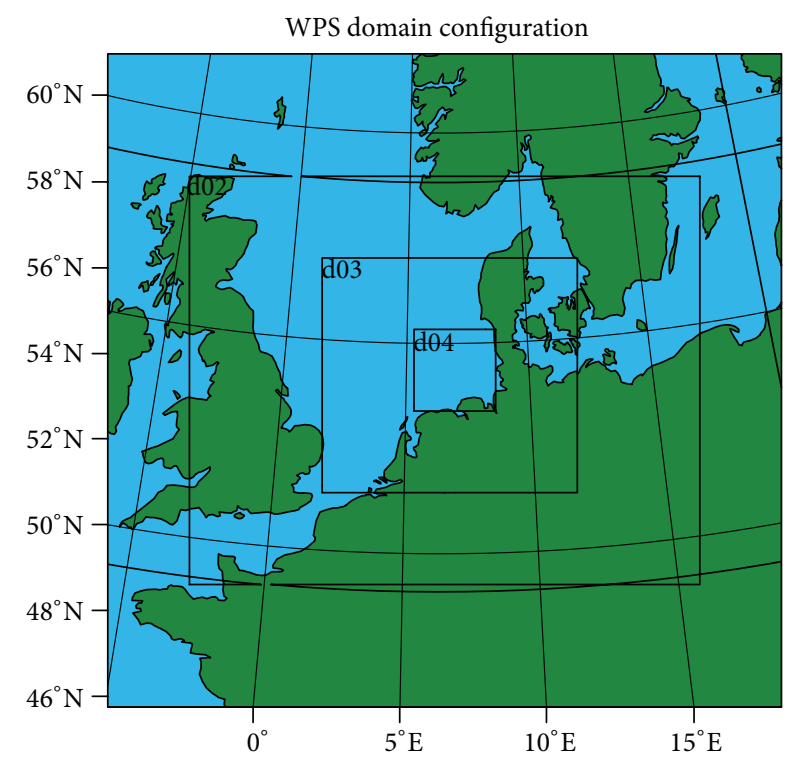

FIGURE 1: WRF modelling domain: $27 \mathrm{~km}$ (d01), $9 \mathrm{~km}$ (d02), $3 \mathrm{~km}$ (d03), and $1 \mathrm{~km}$ (d04) grid spacing.

Domain Setup. The WRF model was run in a series of twoway nested grids (centred in the FINO1 offshore platform at latitude: $54.0^{\circ} \mathrm{N}$ and longitude: $6.35^{\circ} \mathrm{E}$ ). The horizontal grid spacing was refined by a factor of 3 through three nested domains until $1 \mathrm{~km}$ resolution. In particular, the WRF model was built over a parent domain (d01) with $67 \times 65$ horizontal grid points at $27 \mathrm{~km}$, an intermediate nested domain (d02) of $9 \mathrm{~km}$ spatial resolution $(151 \times 121$ grid points), and two innermost domain (d03) with $3 \mathrm{~km}$ spacing $(217 \times 205$ grids) and $1 \mathrm{~km}$ spacing of $202 \times 190$ grids (see Figure 1). On the vertical coordinate, 88 vertical levels were used. The vertical resolution was $10 \mathrm{~m}$ upto $200 \mathrm{~m}$ height to accurately resolve the lower part of the MABL. Above $200 \mathrm{~m}$, grid spacing is progressively stretched.

Initial and Boundary Conditions. The WRF model was used to refine the state of the atmosphere, especially the PBL, by downscaling both the global NCEP final analysis (FNL) data and the Era-Interim reanalysis data produced by the ECMWF. The NCEP FNL data have horizontal resolution of $1 \times 1$ degree $(\sim 100 \mathrm{~km})$ and 52 model levels. The Era-Interim reanalysis project covers the period from 1979 to present and has a spectral T255 horizontal resolution $(\sim 79 \mathrm{~km}$ spacing on a N80 reduced Gaussian grid) and 60 vertical model levels 
[16]. The time step was set equal to 120 seconds to fulfil the Courant-Friedrichs-Lewy (CFL) condition for horizontal and vertical stability and the first 24 hours were discarded as spin-up time of the model.

Topographic Inputs. For the WRF the topographic information was developed using the 20-category moderate resolution imaging spectroradiometer (MODIS) WRF terrain database. The $27 \mathrm{~km}$ domain was based on the 5 minutes $(\sim 9.25 \mathrm{~km})$ global data, the $9 \mathrm{~km}$ domain was based on the 2 minutes $(\sim 3.70 \mathrm{~km})$ data, and the $3 \mathrm{~km}$ and $1 \mathrm{~km}$ domains were based on the 30 seconds $(\sim 900 \mathrm{~m})$ data.

Four-Dimensional Data Assimilation (FDDA). Nudging is one method of FDDA that is implemented in the WRF model. The WRF model supports three types of nudging: the three-dimensional upper-air and/or surface analysis, the observation, and the spectral nudging. Because the purpose of the stable case study was mainly to perform the sensitivity experiments rather than to keep the simulations close to the reanalysis and measurement data, the WRF model was run without analysis and observation nudging for this stable period. When the model was run for the whole March 2005, analysis nudging was configured to nudge temperature, water vapour, mixing ratio, and horizontal wind components on the outermost domain (d01) with time intervals of six hours. The strategy followed for analysis nudging was based on previous studies [17].

Physics Schemes. Microphysics was modelled using the new Thompson scheme with ice, snow, and graupel processes suitable for high-resolution simulations. The rapid radiative transfer model (RRTM) (an accurate and widely used scheme using look-up tables for efficiency) and the Dudhia (a simple downward integration allowing for efficient cloud and clearsky absorption and scattering) schemes were used for the longwave and shortwave radiation options, respectively. The Noah land surface model (LSM) was chosen to simulate soil moisture and temperature and canopy moisture. Finally, the cumulus physics was modelled with the Grell 3D scheme, which is an improved version of the Grell-Devenyi (GD) ensemble scheme that can be used on high resolution (in addition to coarser resolutions). However, the cumulus parameterization was turned off in the fine-grid spacing of $3 \mathrm{~km}$ and $1 \mathrm{~km}$ selected for these simulations. Theoretically, it is only valid for parent grid sizes greater than $9 \mathrm{~km} \mathrm{[10].}$ Finally, four PBL schemes were selected for this study. These include two turbulent kinetic energy (TKE) closure schemes, the Mellor-Yamada-Janjic (MYJ) PBL [18] and the MellorYamada Nakanishi and Niino Level 2.5 (MYNN) PBL [19] and two first-order closure schemes, the Yonsei University (YSU) PBL [20] and the asymmetric convective model version 2 (ACM2) [21]. More details of the model, of the physics schemes and references, could be found in [10].

\section{Results and Discussion}

3.1. Stable Period (16-18 March 2005). In this section, WRF model results are presented and compared with other modelling studies and with high quality observations recorded at the FINO1 offshore platform in the North Sea. The model validation is for stable atmospheric conditions during March 2005. According to Krogsæter [3] and Saint-Drenan et al. [5], at the FINO1 offshore platform stable atmospheric conditions are observed $20 \%$ of the time during spring and early summer. It is well known that the mesoscale models handle both high atmospheric stability and high instability with difficulty due to their PBL schemes. The stable MABL is very complex and its structure is more complicated and variable than the structure of the unstable/neutral MABL [22]. Stable atmospheric conditions are mainly observed during the night and it is well known that the nocturnal boundary layer is driven by two distinct processes: low turbulence and radiative cooling which both are very difficult to describe and to model. Therefore, making precise offshore wind resource maps under stable conditions is a great challenge. For the representative case of the stable MABL, the period from 16 to 18 March 2005 at 00:00 UTC was selected for analysis. Similar studies have been performed in the past for this particular time period and we could therefore compare our methodologies and results with that of other researches (e.g., $[8,11])$.

During the stable period, the synoptic situation over the North Sea is determined by a low-pressure system over the Atlantic and a high-pressure system over the southern Europe, which later in the examined period shifts to the north-west [11]. In Figure 2, we present the temporal variation of the wind and temperature conditions at the FINO1 offshore platform during the stable period. As can be seen in Figure 2, at the beginning of the period very strong southwesterly $\left(\sim 210-240^{\circ}\right)$ winds dominate the area, which later become westerlies $\left(\sim 270^{\circ}\right)$ and slow down. It can be assumed that the MABL structure over the North Sea is influenced by large scale circulations, since no diurnal variation is observed in the air temperature and wind speed. According to Sušelj and Sood [11], the MABL structure over the North Sea is primarily established by the properties of advected air masses and has small or almost no diurnal cycle. For example, at the FINO1 platform mainly during the winter, the southwesterlies to westerlies advect warm air over the cold sea, resulting in a stable MABL, while north-westerlies to northeasterlies advect cold air, resulting in an unstable MABL. In general, we could characterise the period 16-18 March 2005 as a two-day stable period with the air temperature higher than the water temperature and with high wind speeds (see Figure 2). Actually, the FINO1 recordings gave even a $5^{\circ} \mathrm{C}$ difference between the air and the water temperature at the night of 16 March 2005, corresponding closely to stable conditions. Considering the air-water temperature difference is a very simple and pragmatic method of describing the stability conditions. In the current study, this method was shown to be sufficiently precise. In addition, the Richardson number has been also calculated to confirm the stability conditions.

To determine the atmospheric stability, the Richardson number has been calculated using the WRF model outputs. The Richardson number quantifies the respective contribution of the wind shear and the buoyancy to the production 


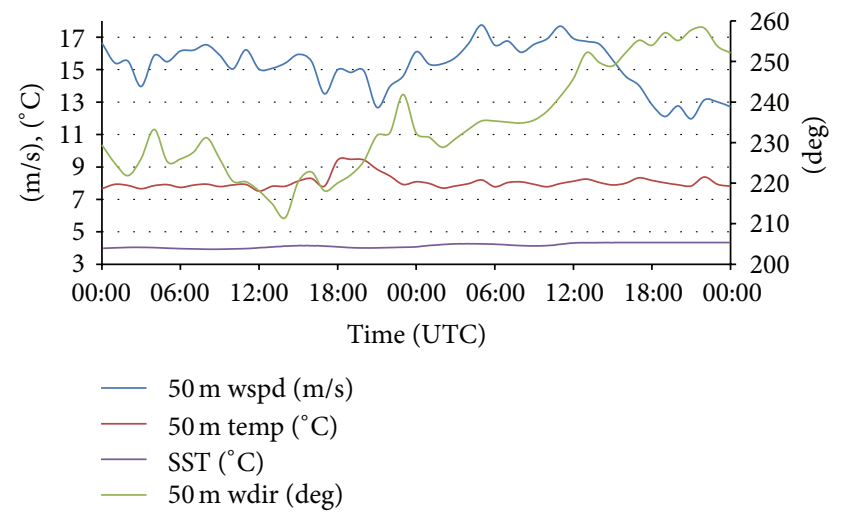

FIGURE 2: Temporal variation of the sea-surface temperature (SST), air temperature $\left({ }^{\circ} \mathrm{C}\right)$, wind speed $(\mathrm{m} / \mathrm{s})$, and wind direction (degree) at $50 \mathrm{~m}$ height, as these were recorded at the FINO1 platform for the stable period 16-18 March 2005 at 00:00 UTC. Temperature and wind speed are represented in the left $y$-axis and the wind direction in the right $y$-axis of the plot.

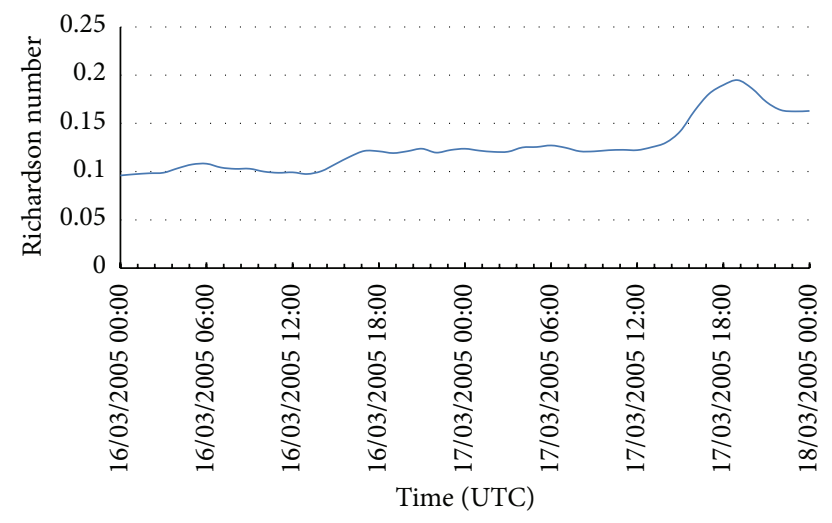

FIgURE 3: Temporal variation of the Richardson number, as this was calculated for the stable period 16-18 March 2005 at 00:00 UTC.

of turbulent kinetic energy [5] and the equation used in the computation of the Richardson number was

$$
\mathrm{Ri}=\frac{g}{\theta_{1}} \frac{\left(\theta_{1}-\theta_{2}\right)\left(z_{1}-z_{2}\right)}{\left(u_{1}-u_{2}\right)^{2}},
$$

where $g$ is the gravitational acceleration, $u_{1}, u_{2}, \theta_{1}$, and $\theta_{2}$ are the wind speed and the virtual potential temperature at the height $z_{1}$ and $z_{2}$, respectively [23].

It is worth noting that negative Richardson numbers indicate unstable conditions; positive values indicate statically stable flows and values close to zero or zero are indicative of neutral conditions. As an example, the Richardson number is plotted in Figure 3 for the period 16-18 March 2005. The positive values of the Richardson number (varying from 0.1 to 0.2 ) confirm the statically stable flows that dominated during this particular time period.

3.1.1. Sensitivity to Horizontal Resolution. Increasing the horizontal resolution in the mesoscale models increases the ability of the models to resolve major features of the topography
TABLE 2: Statistical metrics (MAE in $\mathrm{m} / \mathrm{s}, \mathrm{ME}$ in $\mathrm{m} / \mathrm{s}$, STD of the $\mathrm{ME}$ in $\mathrm{m} / \mathrm{s}$, and $R$ ) for the $100 \mathrm{~m}$ wind speed, so as to evaluate the performance of different horizontal resolutions ( $3 \mathrm{~km}$ versus $1 \mathrm{~km}$ ).

\begin{tabular}{lcccc}
\hline At $100 \mathrm{~m}$ & MAE $(\mathrm{m} / \mathrm{s})$ & $\mathrm{ME}(\mathrm{m} / \mathrm{s})$ & $\mathrm{STD}(\mathrm{m} / \mathrm{s})$ & $R$ \\
\hline $1 \mathrm{~km}$-ERA-I & 2.45 & -2.31 & 1.58 & 0.62 \\
$3 \mathrm{~km}$-ERA-I & $\mathbf{2 . 3 8}$ & $\mathbf{- 2 . 2 7}$ & $\mathbf{1 . 4 7}$ & $\mathbf{0 . 6 6}$ \\
\hline
\end{tabular}

and surface characteristics, such as the coastal boundaries and therefore produces more accurate wind climatologies [4]. Generally speaking, the higher the resolution of the simulation, the better the representation of the atmospheric processes we obtain [24], especially if the terrain is complex [4]. However, it is difficult to define a priori the grid spacing needed to achieve a desired level of accuracy. The sensitivity to horizontal resolutions is thus tested in this section to define optimum grid spacing. For the runs, the ERA-Interim reanalysis was selected to initialise the model and the YSU scheme to model the MABL.

To evaluate the performance of the different horizontal resolutions, four statistical parameters were used: mean absolute error (MAE), mean error (ME), standard deviation (STD) of the ME, and correlation coefficient $(R)$. As an example, statistical metrics for the $100 \mathrm{~m}$ wind speed are shown in Table 2 for the $3 \mathrm{~km}$ and $1 \mathrm{~km}$ spacing. It seems that the $3 \mathrm{~km}$ horizontal resolution results in a slight reduction of MAE, bias, and STD and improves correlations with the observations compared to what has been simulated at the $1 \mathrm{~km}$ spacing. We concluded that the $3 \mathrm{~km}$ is the optimal resolution and that the finest $1 \mathrm{~km}$ spacing does not bring improvement in the WRF results worth considering. It seems that the parameterizations used in the WRF model impose a limit to the downscaling, beyond which there is a minor or any improvement of the model performance. According to Talbot et al. [25], it is beneficial to use very fine horizontal resolution $(\leq 1 \mathrm{~km})$ during stable atmospheric conditions and over heterogeneous surfaces when local properties are required or when resolving small-scale surface features is desirable. In this modelling study, the North Sea can be characterised as a homogeneous surface and therefore there is no advantage of using the computationally expensive $1 \mathrm{~km}$ spacing (as the model resolution increases more computer processing required). It is worth noting that similar results to the one presented in this section were obtained for all the vertical levels below $100 \mathrm{~m}$.

3.1.2. Sensitivity to Input Data. The impact of using different reanalysis datasets on the initialisation of the WRF model is investigated in this section. Comparing the model results when the ERA-Interim and the NCEP data were used at the $3 \mathrm{~km}$ horizontal resolution and with the YSU PBL scheme, it is found that the simulated winds are better correlated with the FINO1 observations and have lower STD and MAE when the ERA-Interim dataset is used (see Table 3). On average over all the vertical levels the ERA-Interim dataset yields $0.91 \mathrm{~m} / \mathrm{s}$ lower wind speeds than recorded, $1.17 \mathrm{~m} / \mathrm{s}$ STD, and correlation between the model and the measurements equal 0.77 . 
TABLE 3: Statistical metrics (MAE in $\mathrm{m} / \mathrm{s}, \mathrm{ME}$ in $\mathrm{m} / \mathrm{s}$, STD of the ME in $\mathrm{m} / \mathrm{s}$, and $R$ ) for wind speed at 8 vertical levels (30-100 m), so as to evaluate the performance of different input datasets (NCEP versus ERA-Interim) at the $3 \mathrm{~km}$ WRF modelling domain.

\begin{tabular}{lccccccccc}
\hline & $30 \mathrm{~m}$ & $40 \mathrm{~m}$ & $50 \mathrm{~m}$ & $60 \mathrm{~m}$ & $70 \mathrm{~m}$ & $80 \mathrm{~m}$ & $90 \mathrm{~m}$ & $100 \mathrm{~m}$ & Average \\
\hline NCEP FNL and YSU PBL & & & & & & & & & \\
MAE (m/s) & 1.09 & 1.09 & 1.06 & 1.23 & 1.44 & 1.94 & 2.20 & 2.40 & 1.56 \\
ME (m/s) & 0.51 & 0.44 & -0.25 & -0.75 & -1.1 & -1.8 & -2.07 & -2.33 & -0.92 \\
STD (m/s) & 1.35 & 1.37 & 1.39 & 1.41 & 1.42 & 1.42 & 1.42 & 1.57 & 1.42 \\
R & 0.63 & 0.62 & 0.62 & 0.62 & 0.62 & 0.62 & 0.63 & 0.59 & 0.62 \\
ERA-I and YSU PBL & & & & & & & \\
MAE (m/s) & 0.89 & 0.90 & 0.88 & 1.07 & 1.29 & 1.84 & 2.10 & 2.38 & $\mathbf{1 . 4 2}$ \\
ME (m/s) & 0.46 & 0.39 & -0.23 & -0.74 & -1.09 & -1.75 & -2.05 & -2.27 & $-\mathbf{0 . 9 1}$ \\
STD (m/s) & 1.01 & 1.05 & 1.10 & 1.14 & 1.18 & 1.21 & 1.23 & 1.47 & $\mathbf{1 . 1 7}$ \\
$R$ & 0.81 & 0.80 & 0.79 & 0.78 & 0.77 & 0.76 & 0.75 & 0.66 & $\mathbf{0 . 7 7}$ \\
\hline
\end{tabular}

TABLE 4: A synopsis of the WRF model configuration used by EDF R\&D for the stable period: 16-18 March 2005.

\begin{tabular}{ll}
\hline Simulation period & $15-20 / 03 / 2005,00: 00$ UTC \\
Model version & V3.4 \\
Domains & 4 \\
Horizontal resolution & $27,9,3$ and $1 \mathrm{~km}$ \\
Grid sizes & $67 \times 65,151 \times 121,217 \times 205$ \\
Vertical resolution & 88 (eta levels) \\
Input data & ERA-Interim \\
Time step & 120 s \\
Outputs frequency & $180,180,60$ and 60 minutes \\
Gridded analysis nudging & NO \\
Nesting & 2 -way nesting \\
Physics schemes & \\
Microphysics & New Thompson \\
Cumulus & Grell $3 \mathrm{D}$ \\
Shortwave & Dudhia \\
Longwave & RRTM \\
LSM & Noah \\
PBL & YSU, MYNN, MYJ, ACM2 \\
\hline
\end{tabular}

Note that in both experiments with different input data an increased MAE with the elevation is observed and the WRF model is found to overestimate the winds below $40 \mathrm{~m}$ and underestimate them above that height. It is also observed that the correlations slightly decrease and the bias continues to increase as the altitude increases; this trend in the mean error and correlation coefficient with the increasing height is an indication that the current model configuration needs further improvement. It seems that this decreasing trend is more pronounced when the ERA-Interim data were used, but the average results (considering the average statistical metrics: correlation, bias, STD, and MAE) were closer to the observations with this dataset. As will be shown later, these reduced correlations with increasing height are a result of several factors including the input data and mainly the PBL scheme.
3.1.3. Sensitivity to PBL Schemes. it is well accepted that the accuracy of the simulated, by the mesoscale models, offshore winds is strongly affected by the PBL schemes [26]. Therefore, a way to improve the WRF performance at the lower levels of the atmosphere is to try different PBL parameterisations. The behaviour of four different PBL schemes (YSU, MYJ, MYNN, and ACM2) on the stable MABL is examined and the importance of defining the appropriate model setup for studying pure offshore wind conditions is noticed in this section. The PBL experiment was run four times; one run for each PBL scheme. A synopsis of the model configuration is given in Table 4.

Statistical metrics (MAE, ME, STD, and $R$ ) for the wind speed at heights from $30 \mathrm{~m}$ upto $100 \mathrm{~m}$ are presented in Table 5. Note that the MYNN PBL scheme predicts lower values of MAE and ME in all vertical levels than the other PBL schemes. It seems that the MYNN scheme is the one that yields to the highest degree of correctness mainly above $50 \mathrm{~m}$ and thus showing in average the best agreement with the FINO1 observations. It is also noticed that the bias between the WRF model and the measurements is lower and close to the surface for the YSU, MYJ, and ACM2 PBL runs, whereas the bias increases with altitude. The YSU run seems to correlate better with the FINO1 measurements than the other PBL schemes below $70 \mathrm{~m}$, but above that height the ME significantly increases and lower values of correlation were found. On the other hand, the MYNN scheme performs almost with the same accuracy at all heights with low values of ME and STD. In particular, the MYNN scheme resulted (in average over all the heights) in $0.01 \mathrm{~m} / \mathrm{s}$ higher wind speeds than measured, STD of $1.21 \mathrm{~m} / \mathrm{s}$, and correlation coefficient equal to 0.66 (see Table 5).

It is well known that the atmospheric stability has a significant effect on the vertical wind profile and on estimates of the wind resource at a given height [4]. A detailed analysis of the offshore vertical wind profile upto hub heights and above is important for a correct estimation of the MABL wind and stability conditions, wind resource, and power forecasting.

The time-averaged vertical profiles of wind speed, temperature, and wind direction for all the PBL runs are provided in Figure 4 for comparison with the FINO1 measurements. 
TABLE 5: Statistical metrics (MAE in m/s, ME in $\mathrm{m} / \mathrm{s}$, STD of the ME in $\mathrm{m} / \mathrm{s}$, and $R$ ) for the wind speed at 8 vertical levels (30-100 $\mathrm{m}$ ), so as to evaluate the performance of four PBL schemes (YSU, MYJ, ACM2, and MYNN) at the $3 \mathrm{~km}$ WRF modelling domain.

\begin{tabular}{|c|c|c|c|c|c|c|c|c|c|}
\hline & $30 \mathrm{~m}$ & $40 \mathrm{~m}$ & $50 \mathrm{~m}$ & $60 \mathrm{~m}$ & $70 \mathrm{~m}$ & $80 \mathrm{~m}$ & $90 \mathrm{~m}$ & $100 \mathrm{~m}$ & Average \\
\hline \multicolumn{10}{|l|}{ YSU PBL } \\
\hline $\operatorname{MAE}(\mathrm{m} / \mathrm{s})$ & 0.89 & 0.90 & 0.88 & 1.07 & 1.29 & 1.84 & 2.10 & 2.38 & 1.42 \\
\hline $\mathrm{ME}(\mathrm{m} / \mathrm{s})$ & 0.46 & 0.39 & -0.23 & -0.74 & -1.09 & -1.75 & -2.05 & -2.27 & -0.91 \\
\hline $\mathrm{STD}(\mathrm{m} / \mathrm{s})$ & 1.01 & 1.05 & 1.10 & 1.14 & 1.18 & 1.21 & 1.23 & 1.47 & 1.17 \\
\hline$R$ & 0.81 & 0.80 & 0.79 & 0.78 & 0.77 & 0.76 & 0.75 & 0.66 & 0.77 \\
\hline \multicolumn{10}{|l|}{ MYJ PBL } \\
\hline $\operatorname{MAE}(\mathrm{m} / \mathrm{s})$ & 1.38 & 1.25 & 1.43 & 1.55 & 1.56 & 1.79 & 1.76 & 1.64 & 1.55 \\
\hline $\mathrm{ME}(\mathrm{m} / \mathrm{s})$ & -1.03 & -0.84 & -1.12 & -1.25 & -1.23 & -1.52 & -1.46 & -1.33 & -1.22 \\
\hline $\mathrm{STD}(\mathrm{m} / \mathrm{s})$ & 1.24 & 1.23 & 1.24 & 1.27 & 1.32 & 1.36 & 1.39 & 1.43 & 1.31 \\
\hline$R$ & 0.68 & 0.67 & 0.67 & 0.66 & 0.64 & 0.63 & 0.63 & 0.65 & 0.65 \\
\hline \multicolumn{10}{|l|}{ ACM2 PBL } \\
\hline $\operatorname{MAE}(\mathrm{m} / \mathrm{s})$ & 1.08 & 0.97 & 1.20 & 1.38 & 1.46 & 1.77 & 1.79 & 1.86 & 1.44 \\
\hline $\mathrm{ME}(\mathrm{m} / \mathrm{s})$ & -0.74 & -0.56 & -0.91 & -1.15 & -1.23 & -1.61 & -1.64 & -1.59 & -1.18 \\
\hline $\mathrm{STD}(\mathrm{m} / \mathrm{s})$ & 1.13 & 1.13 & 1.15 & 1.17 & 1.18 & 1.20 & 1.21 & 1.41 & 1.20 \\
\hline$R$ & 0.67 & 0.66 & 0.65 & 0.63 & 0.61 & 0.61 & 0.60 & 0.56 & 0.62 \\
\hline \multicolumn{10}{|l|}{ MYNN PBL } \\
\hline $\operatorname{MAE}(\mathrm{m} / \mathrm{s})$ & 0.91 & 0.92 & 0.88 & 0.91 & 0.93 & 1.00 & 0.99 & 1.03 & 0.95 \\
\hline $\mathrm{ME}(\mathrm{m} / \mathrm{s})$ & 0.12 & 0.38 & 0.16 & 0.01 & 0.03 & -0.27 & -0.21 & -0.12 & 0.01 \\
\hline $\operatorname{STD}(\mathrm{m} / \mathrm{s})$ & 1.22 & 1.21 & 1.20 & 1.21 & 1.23 & 1.23 & 1.26 & 1.28 & 1.23 \\
\hline$R$ & 0.67 & 0.67 & 0.66 & 0.66 & 0.64 & 0.64 & 0.63 & 0.67 & 0.66 \\
\hline
\end{tabular}

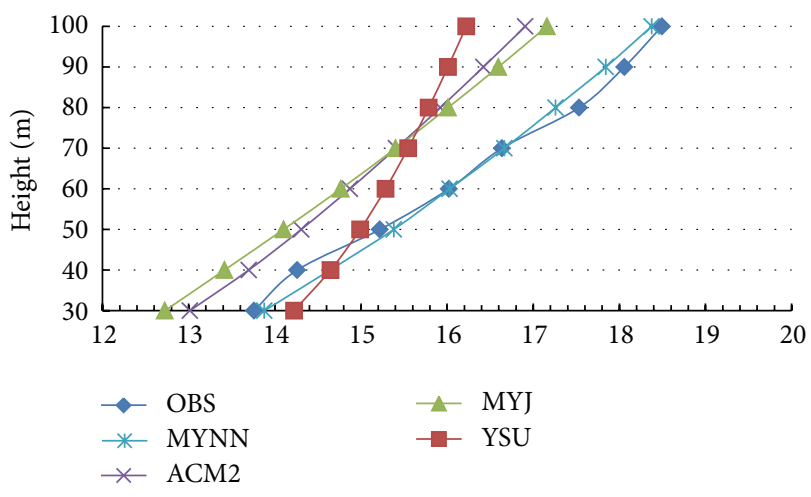

(a) Time-averaged wind speed $(\mathrm{m} / \mathrm{s})$

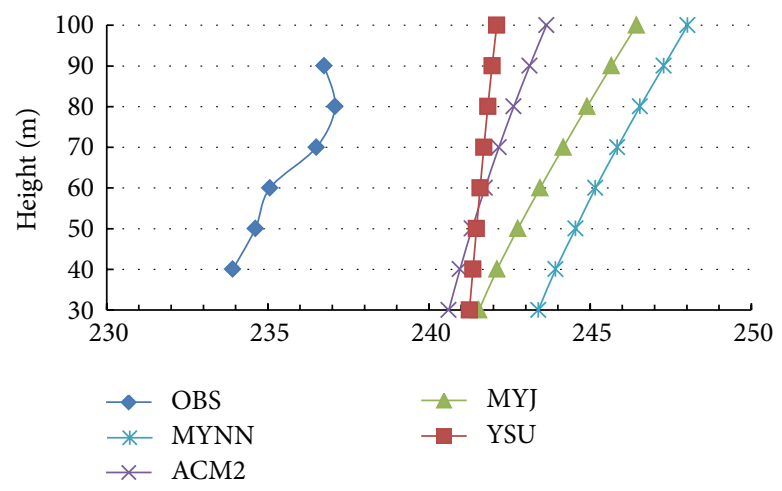

(b) Time-averaged wind direction (degree)

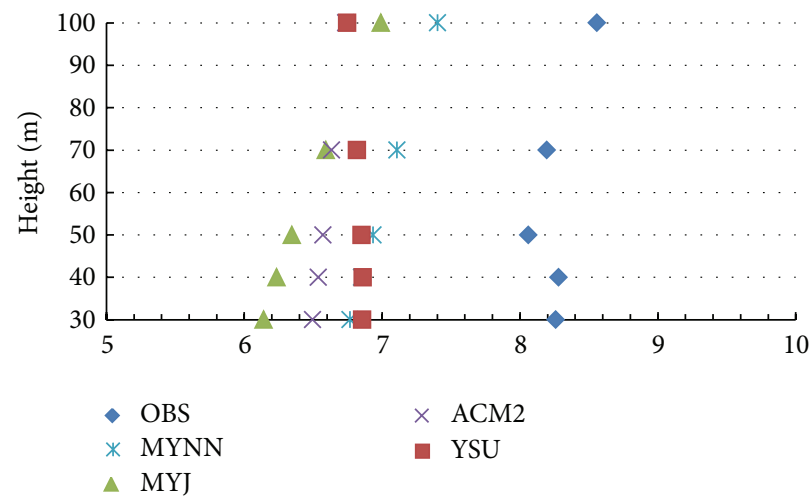

(c) Time-averaged temperature (C)

Figure 4: Time-averaged (16-18 March 2005) vertical profiles upto $100 \mathrm{~m}$ ASL for (a) wind speed (m/s), (b) wind direction (degree), and (c) temperature $\left({ }^{\circ} \mathrm{C}\right)$. The model results of different PBL schemes are compared with the FINO1 measurements. 


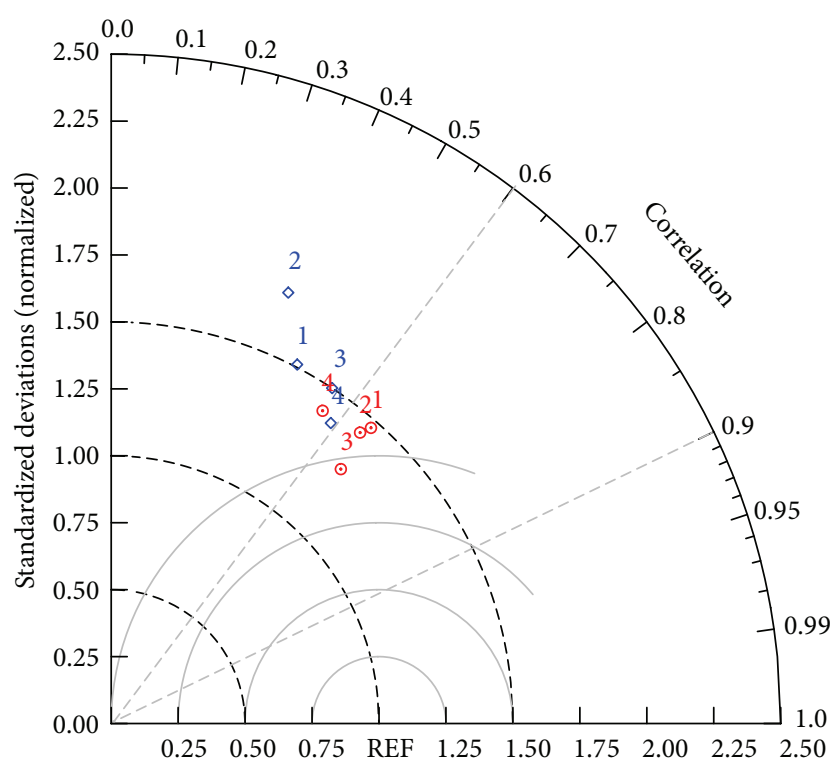

FIGURE 5: Taylor diagram displaying a statistical comparison with four WRF model estimates (YSU: 1, MYJ: 2, MYNN: 3, and ACM2: 4) of the wind speed during the stable period 16-18 March 2005. Red is the EDF statistics and blue is the Muñoz-Esparza et al. [8] statistics.

This kind of representation allows us to have some understanding about the behaviour of different PBL schemes in the lower levels of the MABL. The highly stable conditions observed during the examined period pose a particular challenge. As can be seen in Figure 4, the YSU scheme was in good agreement with the observed data at the $30 \mathrm{~m}$ height, but higher up underestimated the wind resource. This result highlights the importance of studying the whole MABL for offshore wind energy applications. Also, an increase in wind speed with increasing altitude is noticed at all PBL runs, but only the MYNN scheme produces wind speeds which are in exceptionally good agreement with the observations. It seems that the MYNN PBL scheme manages to model the correct amount of mixing in the boundary layer. The MYNN scheme is also shown to be the most consistent with the temperature measurements (approximately $1^{\circ} \mathrm{C}$ difference at $100 \mathrm{~m}$ height) and gives less than $10^{\circ}$ difference in the wind direction at all vertical levels (see Figure 4).

Comparison with Other Modelling Studies. Muñoz-Esparza et al. [8] in their WRF modelling study for the stable period 16-18 March 2005 compared six different PBL schemes. Their model configuration is presented in Table 6.

Statistical metrics (ME, RMSE, and $R$ ) of the $100 \mathrm{~m}$ wind speed for the common PBL runs, as these were calculated by Muñoz-Esparza et al. [8] and by EDF, are shown in Table 7. Note that all PBL runs of this study result in a decreased bias and RMSE as well as in an increased correlation coefficient. The differences between EDF's and Muñoz-Esparza et al.s [8] model setup, such as the input data, the number of the vertical levels, and in general the combination of physics schemes (e.g., microphysics and cumulus), may be a reason for the better accuracy in this study. For example, EDF initialised
TABLE 6: A synopsis of the WRF model configuration used by Muñoz-Esparza et al. [8] for the stable period: 16-18 March 2005.

\begin{tabular}{ll}
\hline Simulation period & $14-18 / 03 / 2005,00: 00$ UTC \\
Model version & V3.2 \\
Domains & 4 \\
Horizontal resolution & $27,9,3$ and $1 \mathrm{~km}$ \\
Vertical resolution & 46 \\
Input data & NCEP \\
Gridded analysis nudging & NO \\
Nesting & 2-way nesting \\
Physics schemes & \\
Microphysics & WSM3 \\
Cumulus & Kain-Fritsch \\
Shortwave & Dudhia \\
Longwave & RRTM \\
LSM & Noah \\
PBL & YSU, MYJ, MYNN, ACM2, \\
& QNSE, BouLac \\
\hline
\end{tabular}

TABLE 7: Muñoz-Esparza et al. [8] versus EDF statistical metrics (ME in $\mathrm{m} / \mathrm{s}$, RMSE in $\mathrm{m} / \mathrm{s}$, and $R$ ) for the $100 \mathrm{~m}$ wind speed, so as to evaluate the WRF performance with different PBL schemes.

\begin{tabular}{lcccccc}
\hline $\begin{array}{l}\text { PBL } \\
\text { schemes }\end{array}$ & $\begin{array}{c}\text { ME } \\
(\mathrm{m} / \mathrm{s})\end{array}$ & $\begin{array}{c}{[8]} \\
\text { RMSE } \\
(\mathrm{m} / \mathrm{s})\end{array}$ & $R(-)$ & $\begin{array}{c}\mathrm{ME} \\
(\mathrm{m} / \mathrm{s})\end{array}$ & $\begin{array}{c}\text { RMSE } \\
(\mathrm{m} / \mathrm{s})\end{array}$ & $R(-)$ \\
\hline YSU & -2.83 & 3.21 & 0.46 & -2.27 & 2.70 & 0.66 \\
MYJ & -1.93 & 2.60 & 0.38 & -1.33 & 1.94 & 0.65 \\
QNSE & -1.23 & 1.90 & 0.53 & - & - & - \\
MYNN & $-\mathbf{0 . 4 4}$ & $\mathbf{1 . 5 6}$ & 0.55 & $-\mathbf{0 . 1 2}$ & $\mathbf{1 . 2 8}$ & $\mathbf{0 . 6 7}$ \\
ACM2 & -1.61 & 2.13 & 0.59 & -1.59 & 2.11 & 0.56 \\
BouLac & -3.08 & 3.42 & 0.46 & - & - & - \\
\hline
\end{tabular}

the model with the ERA-Interim data instead of the NCEP reanalysis and used 88 vertical levels instead of the 46 used by and Muñoz-Esparza et al. [8]. It is well expected that part of the problem with the simulation of stable conditions in the $\mathrm{MABL}$ is having enough vertical levels. A reason is the fact that a stable layer acts as an effective barrier to mixing and if the model layers at the lower levels of the MABL are widely spaced, the simulated barrier may be too weak [4].

Another important point seen in Table 7 is that both Muñoz-Esparza et al. [8] and EDF concluded that the best model performance was observed when the MYNN PBL scheme was selected and that the WRF model tends to underestimate the wind speed at the hub height. The similarities between the PBL experiments of Muñoz-Esparza et al. [8] and EDF are quantified in terms of their correlation, their RMSE, and their STD by using the Taylor diagram [27]. In particular, Figure 5 is a Taylor diagram which shows the relative skill with which the PBL runs of Muñoz-Esparza et al. [8] and of EDF simulate the wind speeds during the stable period 1618 March 2005. Statistics for four PBL runs (YSU: 1, MYJ: 2, MYNN: 3, and ACM2: 4) are used in the plot and the position 
TABLE 8: Statistical metrics (MAE in $\mathrm{m} / \mathrm{s}, \mathrm{ME}$ in $\mathrm{m} / \mathrm{s}$, STD of the ME in $\mathrm{m} / \mathrm{s}$, and $R$ ) for the wind speed at 8 vertical levels (30-100 $\mathrm{m}$ ), so as to evaluate the performance of one- and two-way nesting options at the $3 \mathrm{~km}$ WRF modelling domain.

\begin{tabular}{|c|c|c|c|c|c|c|c|c|c|}
\hline & $30 \mathrm{~m}$ & $40 \mathrm{~m}$ & $50 \mathrm{~m}$ & $60 \mathrm{~m}$ & $70 \mathrm{~m}$ & $80 \mathrm{~m}$ & $90 \mathrm{~m}$ & $100 \mathrm{~m}$ & Average \\
\hline \multicolumn{10}{|c|}{ MYNN and 2-way } \\
\hline $\operatorname{MAE}(\mathrm{m} / \mathrm{s})$ & 0.91 & 0.92 & 0.88 & 0.91 & 0.93 & 1.00 & 0.99 & 1.03 & 0.95 \\
\hline $\mathrm{ME}(\mathrm{m} / \mathrm{s})$ & 0.12 & 0.38 & 0.16 & 0.01 & 0.03 & -0.27 & -0.21 & -0.12 & 0.01 \\
\hline $\operatorname{STD}(\mathrm{m} / \mathrm{s})$ & 1.22 & 1.21 & 1.20 & 1.21 & 1.23 & 1.23 & 1.26 & 1.28 & 1.23 \\
\hline$R$ & 0.67 & 0.67 & 0.66 & 0.66 & 0.64 & 0.64 & 0.63 & 0.67 & 0.66 \\
\hline \multicolumn{10}{|c|}{ MYNN and 1-way } \\
\hline $\operatorname{MAE}(\mathrm{m} / \mathrm{s})$ & 0.97 & 1.00 & 0.98 & 1.00 & 1.02 & 1.07 & 1.08 & 1.11 & 1.03 \\
\hline $\mathrm{ME}(\mathrm{m} / \mathrm{s})$ & 0.17 & 0.43 & 0.21 & 0.05 & 0.08 & -0.22 & -0.17 & -0.07 & 0.06 \\
\hline $\operatorname{STD}(\mathrm{m} / \mathrm{s})$ & 1.28 & 1.28 & 1.28 & 1.30 & 1.33 & 1.34 & 1.36 & 1.40 & 1.32 \\
\hline$R$ & 0.64 & 0.63 & 0.62 & 0.61 & 0.59 & 0.59 & 0.58 & 0.62 & 0.61 \\
\hline
\end{tabular}

of each number appearing on the plot quantifies how closely that run matches observations. If for example, run number 3 (MYNN PBL run) is considered, its pattern correlation with observations is about 0.67 for the EDF MYNN PBL experiment (red colour) and 0.55 for the Muñoz-Esparza et al. [8] MYNN PBL run (blue colour). It seems that the simulated patterns between EDF and [8] that agree well with each other are for the ACM2 PBL run (number 4) and the pattern that has relatively high correlation and low RMSE are for the EDF MYNN PBL run (red-number 3).

3.1.4. Sensitivity to Nesting Options. In the WRF model, the horizontal nesting allows resolution to be focused over a particular region by introducing a finer grid (or grids) into the simulation [10]. Therefore, a nested run can be defined as a finer grid resolution model run in which multiple domains (of different horizontal resolutions) can be run either independently as separate model simulations or simultaneously.

The WRF model supports one-way and two-way grid nesting techniques, where one-way and two-way refer to how a coarse and a fine domain interact. In both the oneway and two-way nesting options, the initial and lateral boundary conditions for the nest domain are provided by the parent domain, together with input from higher resolution terrestrial fields and masked surface fields [10]. In the oneway nesting option, information exchange between the coarse domain and the nest is strictly downscale, which means that the nest does not impact the parent domain's solution. In the two-way nest integration, the exchange of information between the coarse domain and the nest goes both ways. The nest's solution also impacts the parent's solution.

To this point, the best model performance was achieved with the following combination: Era-Interim as input and boundary data, $3 \mathrm{~km}$ as the optimal horizontal resolution, and the MYNN PBL scheme to simulate the MABL. In this section, both the one-way and two-way nesting options with the aforementioned model combination were tested so as to investigate how the different nesting options can affect the WRF performance.

It seems that the differences between the two-way and one-way nesting options are small. However, it can be concluded that the two-way nest integration produces on average wind speeds closer to the FINO1 measurements (see Table 8). When the two-nesting option was selected, the average over all heights ME was $0.01 \mathrm{~m} / \mathrm{s}$ and the STD of the ME was $1.23 \mathrm{~m} / \mathrm{s}$ (instead of $0.06 \mathrm{~m} / \mathrm{s} \mathrm{ME}$ and $1.32 \mathrm{~m} / \mathrm{s}$ STD for the one-way nesting option). As can be also seen in Table 8 , the WRF model resulted in smaller MAE (averaged over all the heights) and correlated better with the observations when the two-way nesting option was selected. It is thus concluded that when the exchange of information between the coarse domain and the nest goes both ways, it results in better model performance.

3.1.5. Summary. The validation of the WRF model at the FINO1 met mast during the stable case study (16-18 March 2005) resulted in the following conclusions in terms of model configuration.

(i) Selecting the finest horizontal resolution of $1 \mathrm{~km}$ instead of the $3 \mathrm{~km}$ does not bring improvement in the WRF results worth considering; it was very time consuming in terms of computational time.

(ii) Using the ERA-Interim reanalysis data instead of the NCEP FNL data allows reducing the bias between simulated and measured winds.

(iii) Changing PBL schemes has a strong impact on the model results. The MYNN PBL scheme was in the best agreement with the observations (confirmed by other modelling studies as well).

(iv) A small improvement in the model performance was observed when the two-way nesting option was used.

3.2. March 2005. Accuracy verification at the FINO1 platform indicated that the WRF methodology developed for the stable period (16-18 March 2005) results in more accurate wind simulation than any other simulation in the study of Muñoz-Esparza et al. [8], though there are similarities between the studies in terms of findings. But, is the concluded WRF model configuration appropriate for other stability conditions (e.g., neutral and unstable) and for longer time periods during which all atmospheric stability conditions are observed? 


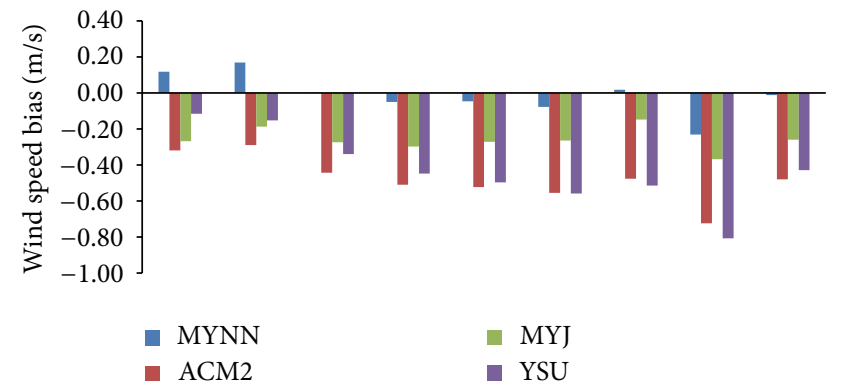

(a)

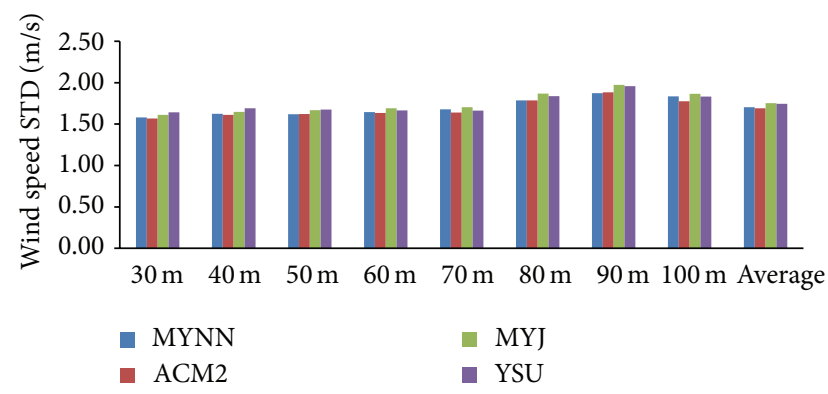

(b)

FIGURE 6: Monthly (March 2005) bias and standard deviation for wind speed at 8 vertical levels (30-100 m) and their average for the four PBL runs (YSU, MYJ, ACM2, and MYNN).

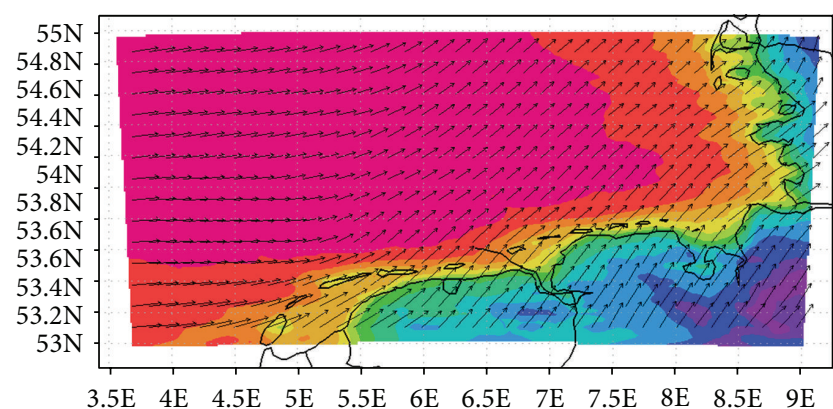

$\begin{array}{lllllllllllll}7.8 & 8.1 & 8.4 & 8.7 & 9 & 9.3 & 9.6 & 9.9 & 10.2 & 10.5 & 10.8 & 11.1\end{array}$

FIgURE 7: Average wind speed $(\mathrm{m} / \mathrm{s})$ and wind direction at $100 \mathrm{~m}$ height over the $3 \mathrm{~km}$ WRF modelling domain during March 2005 when the MYNN PBL scheme was selected.

To answer this question, the WRF model is validated in this section for the whole of March 2005 in which neutral, unstable, and stable atmospheric conditions are observed. To determine the atmospheric stability at the FINO1 met mast for March 2005, the Richardson number was calculated. It was found out that 35\% of the time during March 2005 stable atmospheric conditions were dominant at the FINO1 offshore platform, while $65 \%$ of the time unstable and neutral conditions were observed.

3.2.1. Sensitivity to PBL Schemes. The WRF model is tested with the same four PBL schemes (YSU, MYJ, ACM2, and MYNN) used for the stable scenario. The monthly bias and standard deviation for each height of the FINO1 offshore platform is given in Figure 6 for each PBL run. In Figure 6, we can clearly observe that the MYNN PBL run gives the lowest bias at all vertical heights and the second lowest standard deviation. The biases of the YSU and ACM2 PBL schemes tend to increase as the height increases. As before for the stable case study, we concluded that the MYNN scheme is the one that yields to the highest degree of correctness with the FINO1 observational data. In particular, the MYNN scheme resulted in average over all the heights in $0.01 \mathrm{~m} / \mathrm{s}$ lower wind speeds, STD of $1.71 \mathrm{~m} / \mathrm{s}$, and very high correlation coefficient equal to 0.93 (see Table 9).
TABLE 9: For March 2005, statistical metrics (ME in m/s, STD of the $\mathrm{ME}$ in $\mathrm{m} / \mathrm{s}$, and $R$ ) for wind speed [averaged over all the heights: 30 to $100 \mathrm{~m}$ )], so as to evaluate the performance of four PBL schemes (YSU, MYJ, ACM2, and MYNN) in the WRF model.

\begin{tabular}{lcccc}
\hline PBL & YSU & MYJ & ACM2 & MYNN \\
\hline ME $(\mathrm{m} / \mathrm{s})$ & -0.43 & -0.26 & -0.48 & $-\mathbf{0 . 0 1}$ \\
STD $(\mathrm{m} / \mathrm{s})$ & 1.75 & 1.75 & 1.69 & $\mathbf{1 . 7 1}$ \\
$R$ & 0.92 & 0.92 & 0.92 & $\mathbf{0 . 9 3}$ \\
\hline
\end{tabular}

In Figure 7, a map plot of the average $100 \mathrm{~m}$ wind speed and wind direction, as these were simulated during March 2005 from the MYNN PBL run over the $3 \mathrm{~km}$ WRF modelling domain, is provided. At the FINO1 mast (latitude: $54.0^{\circ} \mathrm{N}$ and longitude: $6.35^{\circ} \mathrm{E}$ ) and the areas nearby the platform over the North Sea, the WRF model simulated hub height-wind speeds of the order of $11.2 \mathrm{~m} / \mathrm{s}$ and westerly to southwesterly direction. In Figure 8, the wind roses are shown for March 2005 from both the FINO1 observations and all the WRF PBL simulations. It seems that the model in every PBL simulation overestimates the occurrence of wind speed in the range 12$16 \mathrm{~m} / \mathrm{s}$ and results in a small veering of the winds in the clockwise direction between $0^{\circ}$ and $180^{\circ}$.

3.2.2. Error Analysis and Q-Q Plots. In Figure 9, the Q$\mathrm{Q}$ plots of the $100 \mathrm{~m}$ wind speed for March 2005 display a quantile-quantile plot of two samples: modelled versus observed. Each blue point in the Q-Q plots corresponds to one of the quantiles of the distribution the modelled wind follows and is plotted against the same quantile of the FINO1 observations' distribution. If the samples do come from the same distribution, the plot will be linear and the blue points will lie on the $45^{\circ}$ line $y=x$.

As can be seen in Figure 9, the two distributions (the one modelled with the MYNN PBL scheme versus the observed one at FINO1) being compared are almost identical. The blue points in the Q-Q plot are closely following the $45^{\circ}$ line $y=x$ with high correlation coefficient equal to 0.93 (see Table 9). The hourly observed and modelled wind speeds for March 2005 follow the Weibull distribution and upon closer inspection of Figure 10 the Weibull distribution resulted from the MYNN PBL run is the one that fits very 


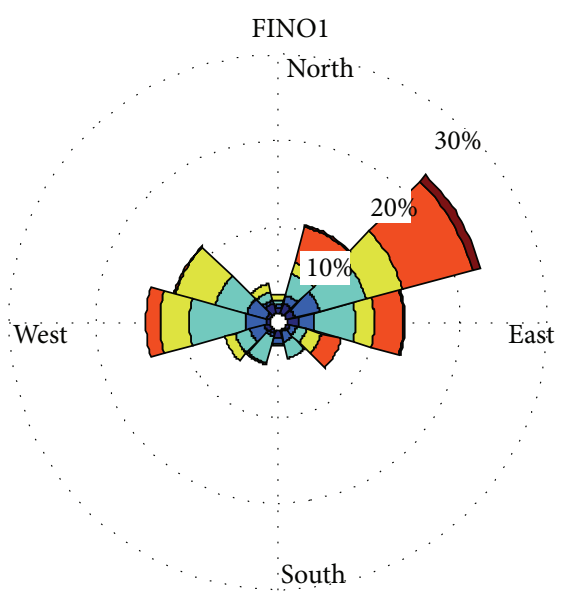

(a)

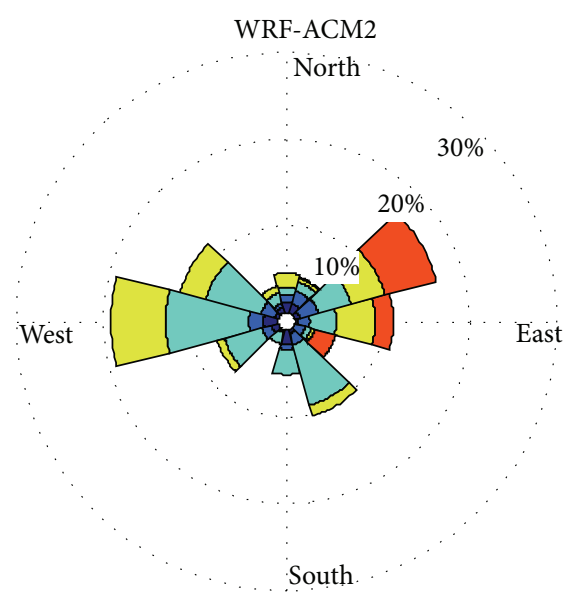

(b)

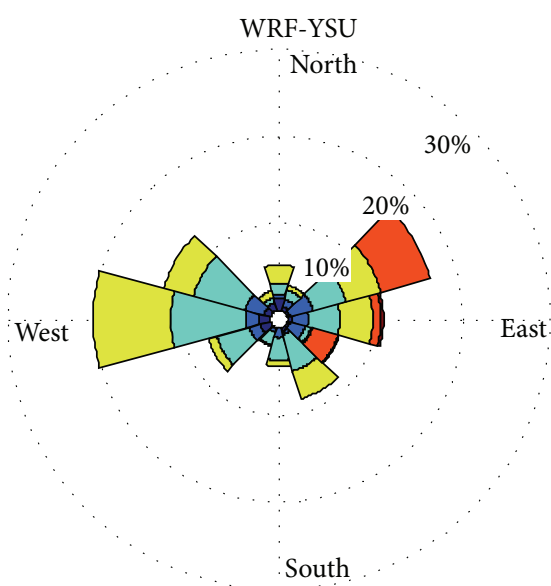

(c)

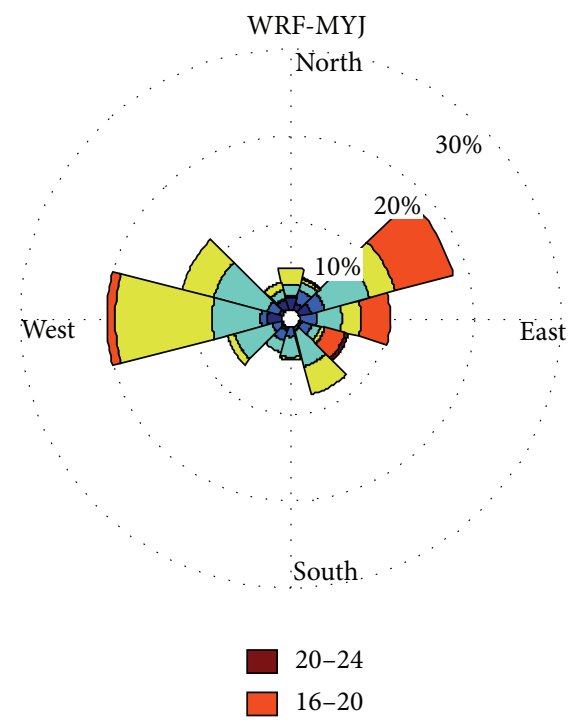

(d)

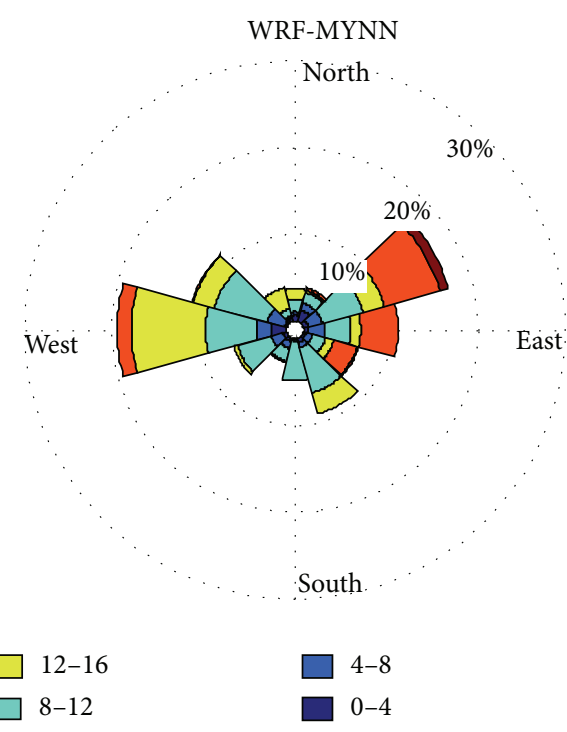

(e)

Figure 8: Wind roses based on March 2005 data from the FINO1 measurements and the WRF PBL runs (ACM2, YSU, MYJ, and MYNN) at $100 \mathrm{~m}$ height.

well with the FINO1 observed distribution at the $100 \mathrm{~m}$ height. In particular, the shape and scale parameters of the Weibull distribution, as these were calculated with the FINO1 measurements, were 2.51 and 12.74 , respectively. The shape parameter modelled by the WRF model varied from 2.20 to 2.85 and the scale parameter ranged from 11.41 to 12.51 for the different PBL schemes used. However, only the MYNN PBL scheme resulted in shape and scale parameters closer to the one observed at the offshore platform (see Figure 10).

In order to further understand the performance of the WRF model and show the variation of the model results, in this section an error analysis is also performed. In general, the errors are assumed to follow normal distributions about their mean value and so the standard deviation is the measurement of the uncertainty. If it turns out that the random errors in the process are not normally distributed, then any inferences made about the process may be incorrect. In Figure 9, we provide a normal probability plot of the $\mathrm{ME}$ of the $100 \mathrm{~m}$ wind speed. The plot includes a reference line indicating that the ME of the wind speed (blue points) closely follows the normal distribution. Figure 9 also shows a histogram of the wind speed mean error. In the $y$-axis of this histogram we have the number of records with a particular velocity error. The blue bars of the histogram show the relative frequency with which each wind speed error (which is shown along the $x$ axis) occurs. Clearly the ME follows the normal distribution and the mean is very close to zero, which is an indication that the mean error is unbiased.

\section{Conclusions}

The main goals of the present study were to achieve a better understanding of the offshore wind conditions, to accurately 


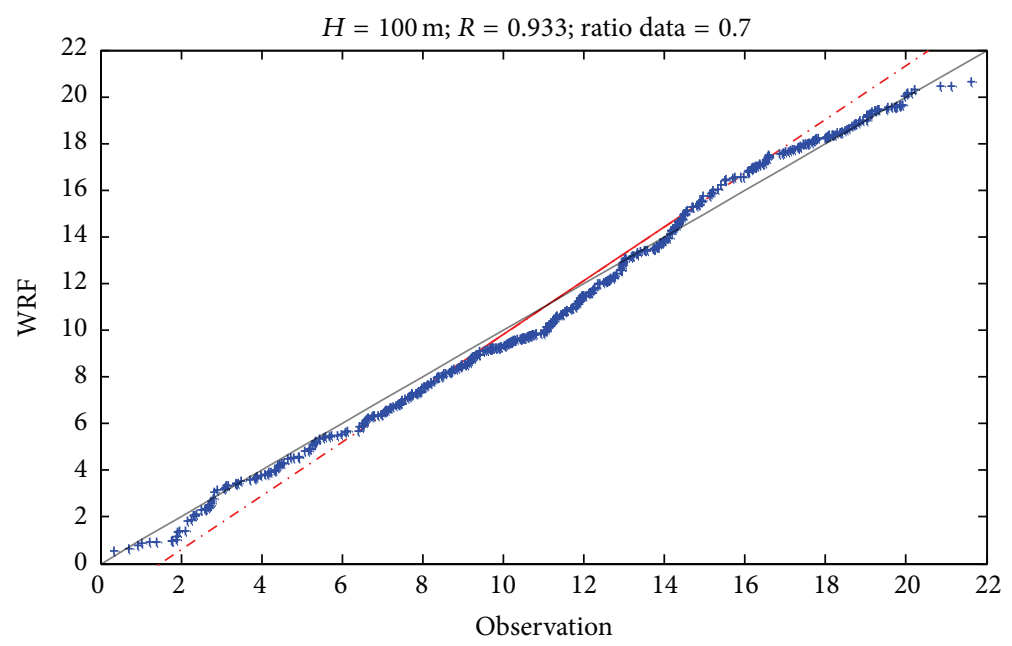

(a)

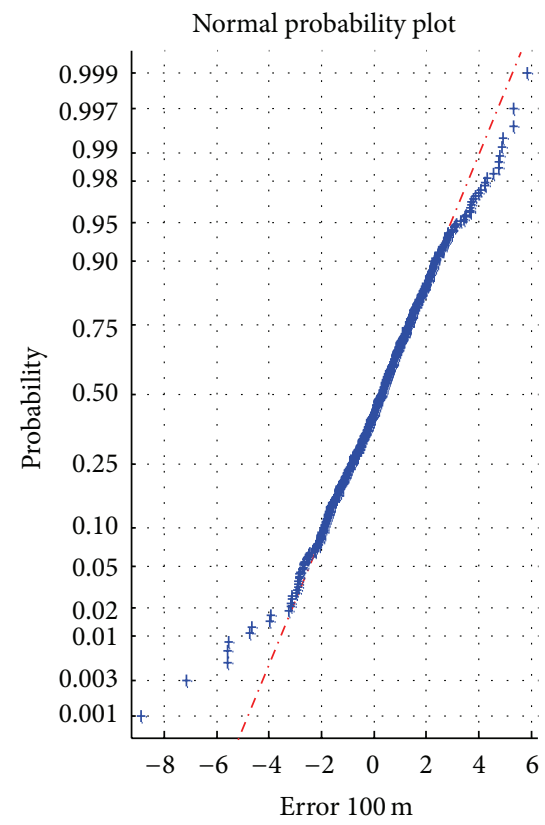

(b)

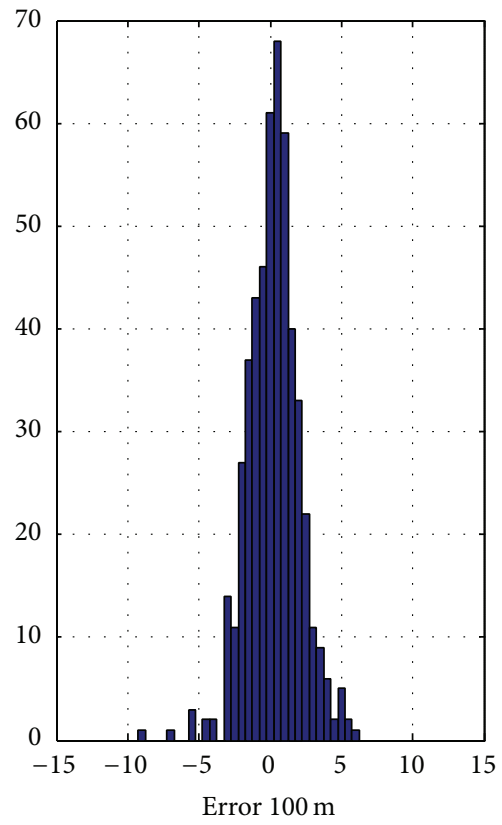

(c)

FIGURE 9: (a) Q-Q plot: the WRF MYNN PBL run ( $y$-axis) against the FINO1 $100 \mathrm{~m}$ wind speed distribution ( $x$-axis). (b) Normal distribution against the $100 \mathrm{~m}$ wind speed $\mathrm{ME}$ and (c) histogram of the wind speed ME.

simulate the wind flow and atmospheric stability occurring offshore over the North Sea, and to develop a mesoscale modelling approach that could be used for more accurate WRA. In order to achieve all these goals, this paper examined the sensitivity of the performance of the WRF model to the use of different initial and boundary conditions, horizontal resolutions, and PBL schemes at the FINO1 offshore platform.

The WRF model methodology developed in this study appeared to be a very valuable tool for the determination of the offshore wind and stability conditions in the North Sea. It resulted in more accurate wind speed fields than the one simulated in previous studies, though there were similar findings. It was concluded that the mesoscale models must be adaptive in order to increase their accuracy. For example, the atmospheric stability on the MABL (especially the stable atmospheric conditions), the topographic features in order to adjust the horizontal resolution accordingly, and the input datasets are needed to be taken into account.

It was concluded that the $3 \mathrm{~km}$ spacing is an optimal horizontal resolution for making precise offshore wind resource maps. Also, using the ERA-Interim reanalysis data instead of the NCEP FNL data allows us to reduce the bias between simulated and measured winds. Finally, it was found that changing PBL schemes has a strong impact on the model results. In particular, for March 2005 the MYNN PBL run yields in the best agreement with the observations with $0.01 \mathrm{~m} / \mathrm{s}$ bias, standard deviation of $1.71 \mathrm{~m} / \mathrm{s}$, and correlation of 0.93 (averaged over all the vertical levels). 


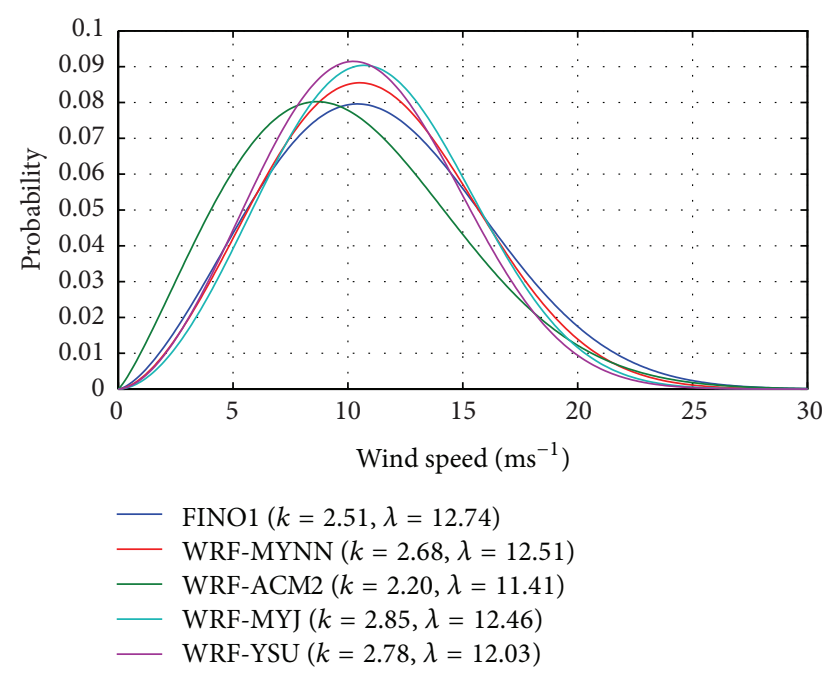

FIgURE 10: Weibull distribution based on March 2005 data from the FINO1 measurements and the WRF PBL runs (ACM2, YSU, MYJ, and MYNN) at $100 \mathrm{~m}$ height.

In future studies, in order to increase the reliability of the wind simulations and forecasting, it is necessary to expand the simulation period as long as possible.

\section{Conflict of Interests}

The authors declare that there is no conflict of interests regarding the publication of this paper.

\section{References}

[1] O. Krogsæter, J. Reuder, and G. Hauge, "WRF and the marine planetary boundary layer," in EWEA, pp. 1-6, Brussels, Belgium, 2011.

[2] A. C. Fitch, J. B. Olson, J. K. Lundquist et al., "Local and Mesoscale Impacts of Wind Farms as Parameterized in a Mesoscale NWP Model," Monthly Weather Review, vol. 140, no. 9, pp. 3017-3038, 2012.

[3] O. Krogsæter, "One year modelling and observations of the Marine Atmospheric Boundary Layer (MABL)," in NORCOWE, pp. 10-13, 2011.

[4] M. Brower, J. W. Zack, B. Bailey, M. N. Schwartz, and D. L. Elliott, "Mesoscale modelling as a tool for wind resource assessment and mapping," in Proceedings of the 14th Conference on Applied Climatology, pp. 1-7, American Meteorological Society, 2004.

[5] Y.-M. Saint-Drenan, S. Hagemann, L. Bernhard, and J. Tambke, "Uncertainty in the vertical extrapolation of the wind speed due to the measurement accuracy of the temperature difference," in European Wind Energy Conference \& Exhibition (EWEC '09), pp. 1-5, Marseille, France, March 2009.

[6] B. Cañadillas, D. Muñoz-esparza, and T. Neumann, "Fluxes estimation and the derivation of the atmospheric stability at the offshore mast FINO1," in EWEA Offshore, pp. 1-10, Amsterdam, The Netherlands, 2011.

[7] D. Muñoz-Esparza and B. Cañadillas, "Forecasting the Diabatic Offshore Wind Profile at FINO1 with the WRF Mesoscale Model," DEWI Magazine, vol. 40, pp. 73-79, 2012.
[8] D. Muñoz-Esparza, J. Beeck Van, and B. Cañadillas, "Impact of turbulence modeling on the performance of WRF model for offshore short-term wind energy applications," in Proceedings of the 13th International Conference on Wind Engineering, pp. 1-8, 2011.

[9] M. Garcia-Diez, J. Fernandez, L. Fita, and C. Yague, "Seasonal dependence of WRF model biases and sensitivity to PBL schemes over Europe," Quartely Journal of Royal Meteorological Society, vol. 139, pp. 501-514, 2013.

[10] W. Skamarock, J. Klemp, J. Dudhia et al., "A description of the advanced research WRF version 3," NCAR Technical Note 475+STR, 2008.

[11] K. Sušelj and A. Sood, "Improving the Mellor-Yamada-Janjić Parameterization for wind conditions in the marine planetary boundary layer," Boundary-Layer Meteorology, vol. 136, no. 2, pp. 301-324, 2010.

[12] F. Kinder, "Meteorological conditions at FINO1 in the vicinity of Alpha Ventus," in RAVE Conference, Bremerhaven, Germany, 2012.

[13] J. M. Potts, "Basic concepts," in Forecast Verification: A Practitioner's Guide in Atmospheric Science, I. T. Jolliffe and D. B. Stephenson, Eds., pp. 11-29, John Wiley \& Sons, New York, NY, USA, 2nd edition, 2011.

[14] E. M. Giannakopoulou and R. Toumi, "The Persian Gulf summertime low-level jet over sloping terrain," Quarterly Journal of the Royal Meteorological Society, vol. 138, no. 662, pp. 145-157, 2012.

[15] E. M. Giannakopoulou and R. Toumi, "Impacts of the Nile Delta land-use on the local climate," Atmospheric Science Letters, vol. 13, no. 3, pp. 208-215, 2012.

[16] D. P. Dee, S. M. Uppala, A. J. Simmons et al., “The ERA-Interim reanalysis: configuration and performance of the data assimilation system," Quarterly Journal of the Royal Meteorological Society, vol. 137, no. 656, pp. 553-597, 2011.

[17] P. Liu, A. P. Tsimpidi, Y. Hu, B. Stone, A. G. Russell, and A. Nenes, "Differences between downscaling with spectral and grid nudging using WRF," Atmospheric Chemistry and Physics, vol. 12, no. 8, pp. 3601-3610, 2012.

[18] G. L. Mellor and T. Yamada, "Development of a turbulence closure model for geophysical fluid problems," Reviews of Geophysics \& Space Physics, vol. 20, no. 4, pp. 851-875, 1982.

[19] M. Nakanishi and H. Niino, "An improved Mellor-Yamada Level-3 model with condensation physics: its design and verification," Boundary-Layer Meteorology, vol. 112, no. 1, pp. 1-31, 2004.

[20] S.-Y. Hong, Y. Noh, and J. Dudhia, "A new vertical diffusion package with an explicit treatment of entrainment processes," Monthly Weather Review, vol. 134, no. 9, pp. 2318-2341, 2006.

[21] J. E. Pleim, "A combined local and nonlocal closure model for the atmospheric boundary layer. Part II: application and evaluation in a mesoscale meteorological model," Journal of Applied Meteorology and Climatology, vol. 46, no. 9, pp. 13961409, 2007.

[22] B. Storm, J. Dudhia, S. Basu, A. Swift, and I. Giammanco, "Evaluation of the weather research and forecasting model on forecasting low-level jets: implications for wind energy," Wind Energy, vol. 12, no. 1, pp. 81-90, 2009.

[23] J. L. Woodward, "Appendix A: atmospheric stability classification schemes," in Estimating the Flammable Mass of a Vapor Cloud, pp. 209-212, American I. Wiley Online Library, 1998. 
[24] L. Fita, J. Fernández, M. García-Díez, and M. J. Gutiérrez, "SeaWind project: analysing the sensitivity on horizontal and vertical resolution on WRF simulations," in Proceedings of the 2nd Meeting on Meteorology and Climatology of the Western Mediterranean (JMCMO '10), 2010.

[25] C. Talbot, E. Bou-Zeid, and J. Smith, "Nested mesoscale largeEddy simulations with WRF: performance in real test cases," Journal of Hydrometeorology, vol. 13, no. 5, pp. 1421-1441, 2012.

[26] S. Shimada, T. Ohsawa, T. Kobayashi, G. Steinfeld, J. Tambke, and D. Heinemann, "Comparison of offshore wind speed profiles simulated by six PBL schemes in the WRF model," in Proceedings of the 1st International Conference Energy \& Meteorology Weather \& Climate for the Energy Industry (IECM '11), pp. 1-11, November 2011.

[27] K. E. Taylor, "Summarizing multiple aspects of model performance in a single diagram," Journal of Geophysical Research D, vol. 106, no. 7, pp. 7183-7192, 2001. 

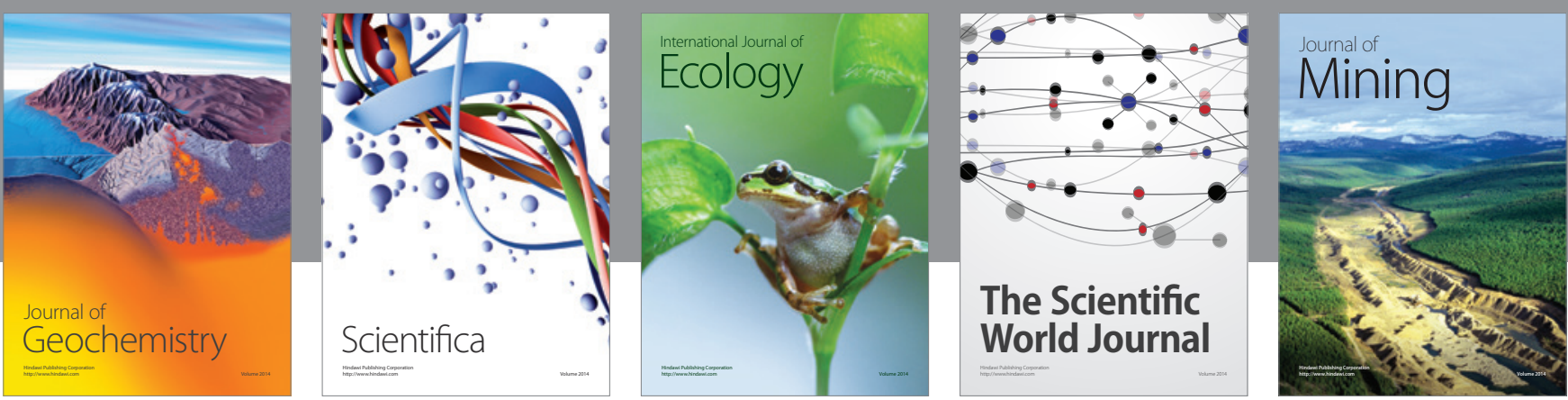

The Scientific World Journal
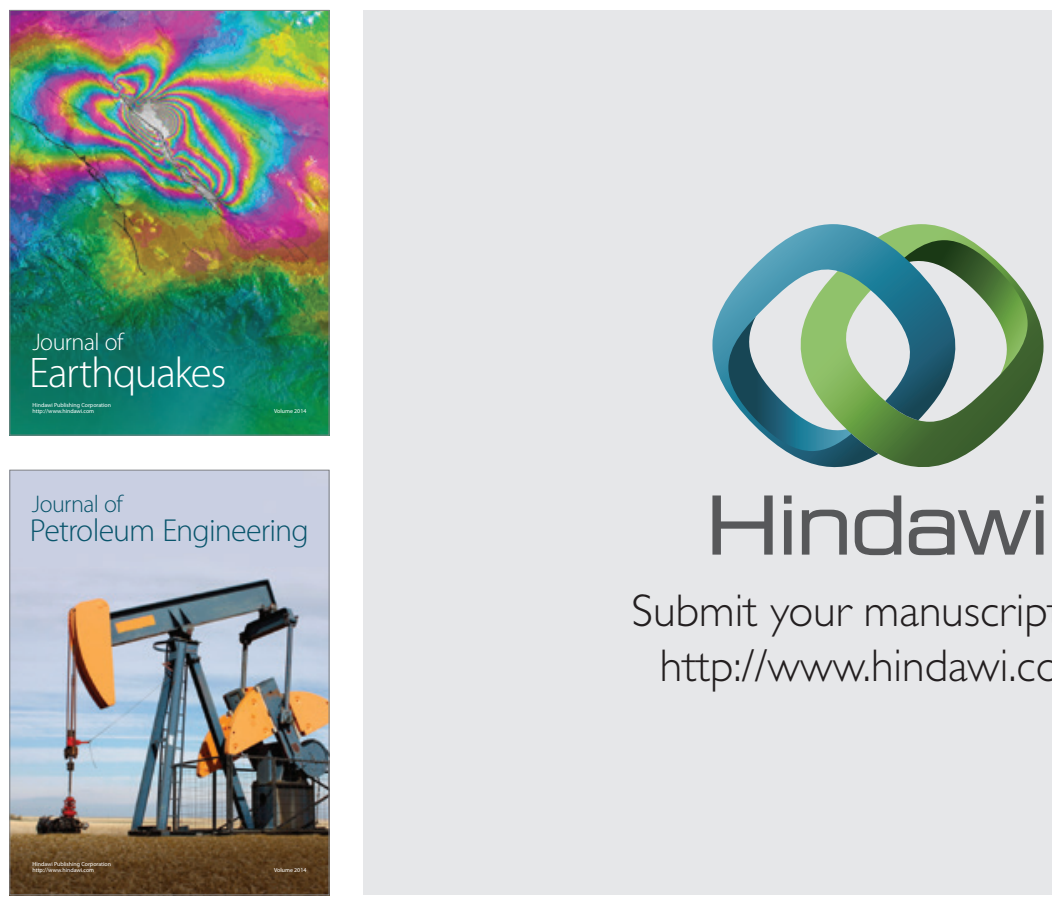

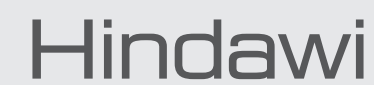

Submit your manuscripts at

http://www.hindawi.com
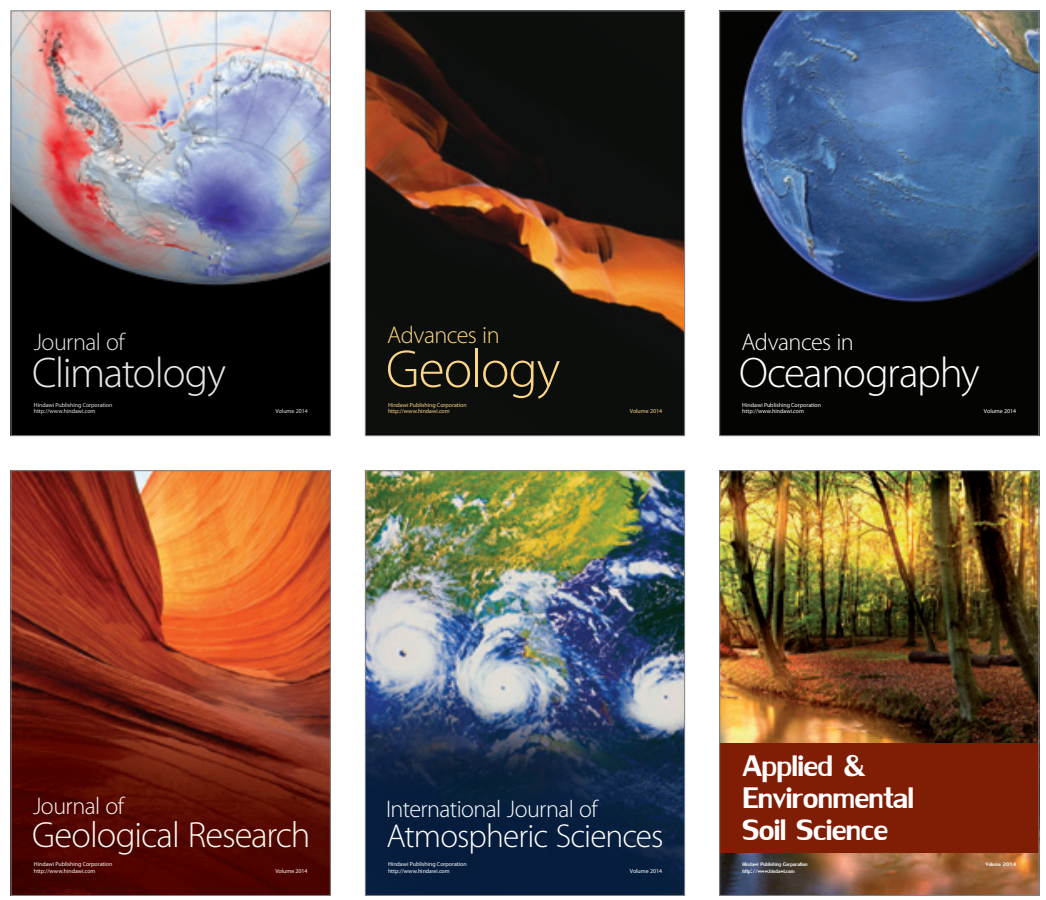
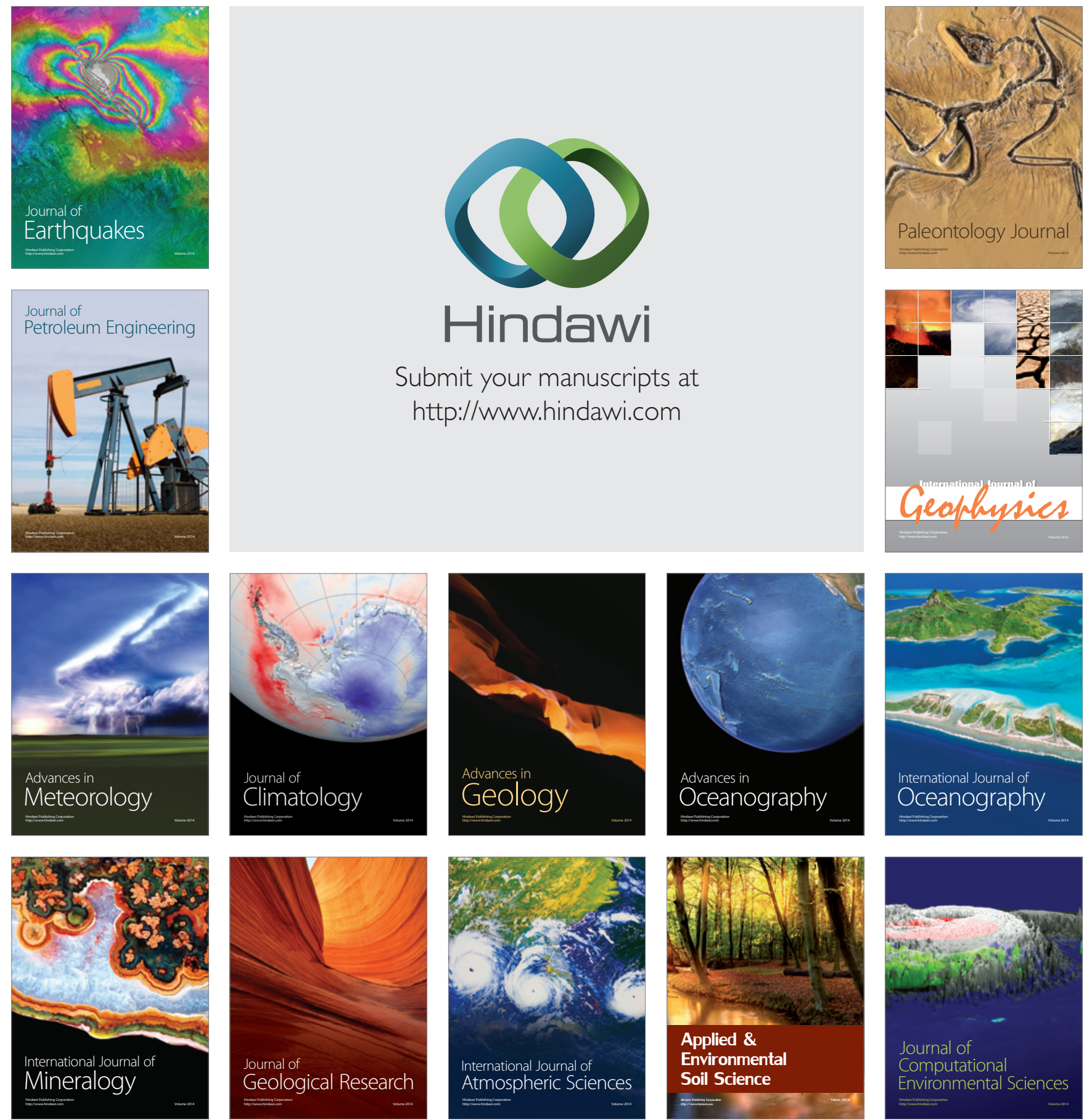